\title{
Ex-situ ellipsometric study of the nanolayers of dihydroantracene oligoperoxide adsorbed on glass surface
}

\author{
${ }^{1,2}$ Kostruba A., ${ }^{3}$ Stetsyshyn Yu., ${ }^{3}$ Zaichenko A., ${ }^{3}$ Mitina N., ${ }^{3}$ Zolobko O. \\ ${ }^{1}$ Institute of Physical Optics, 23 Dragomanov St., 79005 Lviv, Ukraine \\ ${ }^{2}$ Lviv Academy of Commerce, 9 Samchuk St., 79011 Lviv, Ukraine, \\ E-mail: amkostr@lac.lviv.ua \\ ${ }^{3}$ Lviv Polytechnic National University, 12 S. Bandera St., 79013 Lviv, Ukraine
}

Received: 17.07 .2010

\begin{abstract}
In this work we study kinetics of adsorption process and structure of nanolayers formed by a new oligoperoxide with dihydroantracene units. It is shown that the structure of oligoperoxide nanolayer adsorbed on a glass surface depends on the concentration of polymer in aqueous solution and the duration of adsorption process. The adsorption isotherm curves reveal a complicated time dependences explained by changes occurring in the conformation of macromolecules on the solid surface. A stable equilibrium of the structure of adsorption nanolayers is reached in a few tens of minutes.
\end{abstract}

Keywords: oligoperoxides, adsorption, nanolayers, ellipsometry

PACS: 42.62.Be, $42.70 . J k$

UDC: 535.39

\section{Introduction}

Surface modification is often used in order to control such material features as wettability, reactivity, biocompatibility, adhesion, and some optical properties. Modifications of this kind are widely applied in a modern nanotechnology [1-5]. Adsorption of oligomeric macromolecules of liquids on a solid surface represents one of the most applicable techniques employed with this aim. From this point of view, the structure of oligomeric nanolayers and the kinetics of appropriate adsorption process are of a great interest. In order to characterise the surface structure and study the kinetics of the surface processes, one can use a very sensitive ellipsometric technique. The latter enables one to determine the optical parameters of the surface layers and their thickness with a great accuracy [68].

In our earlier work [9], we have suggested a method for depositing a polymer layer based on adsorption of the latter using aqueous solution of fluorescent oligoperoxide (OP) with europium complexes. A series of new OPs containing bioactive units are also promising in this respect. Moreover, the OP having [1-(methacryloylamino)-9,10-dioxo4[(phenoxysulfinyl)amino]-9,10-dihydroanthracene] units in the macromolecular structure is interesting as an antibacterial and antitumour remedy [10]. As shown in our earlier 
works $[6,9]$, the kinetic characteristics of adsorption of the OPs and the structure of adlayers depend essentially on the macromolecular composition. The nature and structure of the OP nanolayers are influential in what concerns the interactions with biological objects (microorganisms, cells, proteins, etc.). Therefore, characterisation of the nanolayer structure is an urgent problem. In this relation we would mention that the possibilities of the ellipsometric analysis of transparent heterogeneous layers deposited on glass substrates are still disclosed not enough (see [11]).

In this work, we have studied the kinetics of formation and the structure of nanolayers of the adsorbed OP composed of 1-(methacryloylamino)-9,10-dioxo$4[$ (phenoxysulfinyl)amino]-9,10-dihydroanthracene. The effective surface fraction $x$ modified by the OP has been evaluated issuing from the receding contact angles determined in our recent work [12].

\section{Experimental details}

\subsection{Materials}

Carbon chain OP derived from a vinyl acetate (VA), maleic anhydride (MA), 2-tertbutylperoxy-2-methyl-5-hexene-3-yne (VEP), butylacrylate (Bac) and 1-(methacryloylamino)-9,10-dioxo-4[(phenoxysulfinyl)amino]-9,10-dihydroanthracene (Ant) (VA-VEP-MA-Bac-Ant 10.7:34.0:38.92:12.2:0.17\% mol) were obtained through copolymerisation of the solution at $333 \mathrm{~K}$ in ethyl acetate, using azobisisobutyronitrile (AIBN) as an initiator [6]. The structure of the OP polymers thus obtained is presented in Scheme 1.

\subsection{Adsorption of oligoperoxide}

Glass plates were immersed into a $5 \%$ water-ammonia solution with a pre-defined OP polymer concentrations $(C=0.6,1.0$ and $2.5 \%)$ and then incubated in a water bath at $20 \pm 0.1^{\circ} \mathrm{C}$. The adsorption time $t$ was varied between 0.5 and $120 \mathrm{~min}$. After the immersion stage, the excess solution was removed from each plate by centrifuging.

\subsection{Ellipsometric measurement technique}

The thickness and the optical parameters of the adsorbed polymer nanolayers were obtained experimentally for different concentrations of the OP solutions using ellipsometric measurements described in our earlier work [9]. We used an $e x$-situ ellipsometric technique. The corresponding ellipsometric measurements were carried out for each specimen both before and after formation of the layers.

A null-ellipsometer LEF-3M produced by the Institute for Semiconductors Physics (Novosibirsk, Russia) had a PCSA (polariser-compensator-specimen-analyser) scheme and provided the accuracy of $0.01^{\circ}$ for the angular orientation of its optical elements. A single-mode He-Ne laser with the light wavelength of $\lambda=632.8 \mathrm{~nm}$ was used as a light source. The polarisation parameters of light reflected from specimens (the angles $\Psi$ and $\Delta$ ) were determined using a four-zone technique [13] for the incident angles varied in the region $58-63^{\circ}$, with the step of $1^{\circ}$. 


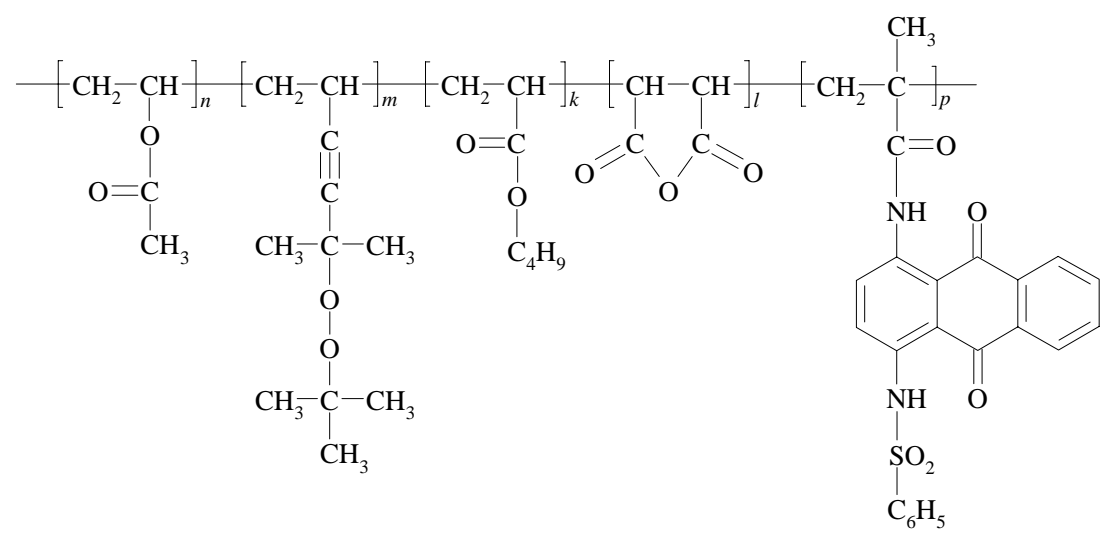

Scheme 1. Molecular formula of VA-VEP-MA-Bac-Ant OP ( $n=10.7 \% \mathrm{~mol}$, $\left.\mathrm{m}=34.0 \% \mathrm{~mol}, \mathrm{k}=38.92 \% \mathrm{~mol}, \mathrm{l}=12.2 \% \mathrm{~mol}, \mathrm{p}=0.17 \% \mathrm{~mol}, \mathrm{M}_{\mathrm{n}}=3500 \% \mathrm{~mol}\right)$.

In frame of the surface model used by us and under optimal experimental conditions, the accuracy for the parameters of the layers under study was described by the errors $\delta d_{\mathrm{f}}$ $= \pm 0.05 \mathrm{~nm}$ for the thickness and $\delta n_{\mathrm{f}}= \pm 0.001$ for the refractive index of the layer. These values were obtained using computation experiments performed for a well defined surface model "glass-polymer layer".

The refractive index of the adsorbed surface layer provides information on the volume fraction of polymer in that layer. Therefore, the density of macromolecular package on the solid surface can be estimated basing on the ellipsometry technique. The volume fraction of the polymer in a heterogeneous surface layer may be calculated using the Maxwell-Garnett effective-medium theory [13, 14]:

$$
q=\frac{V_{p o l}}{V_{f}}=\frac{n_{e}^{2}-n_{m}^{2}}{n_{e}^{2}+2 n_{m}^{2}} \frac{n_{p o l}^{2}+2 n_{m}^{2}}{n_{p o l}^{2}-n_{m}^{2}},
$$

where $V_{p o l}$ denotes the total volume occupied by polymer molecules, $V_{f}$ the total volume of heterogeneous surface layer, $n_{e}$ the refractive index of surface film obtained from the ellipsometric measurements, $n_{p o l}$ the bulk refractive index of polymer material obtained from refractometric measurements, and $n_{m}$ the refractive index of surrounding medium (solvent or air) that causes heterogeneity of a polymer nanolayer structure.

The adsorption value may be evaluated from the ellipsometric data via the relation [6]

$$
A=\frac{V_{p o l}}{V_{f}} \rho d_{f},
$$

where $\rho$ is the bulk polymer density, $d_{f}$ the thickness of polymer nanolayer, and $\left(V_{p o l} / V_{f}\right) \rho=q \cdot \rho$ the density of polymer substance inside a heterogeneous adlayer. It is obvious that the product of the heterogeneous adlayer thickness and the density of polymer substance inside this layer gives the surface density of the adsorbed material or, in 
other words, the adsorption parameter. Then the surface area occupied by a single OP molecule may be estimated using the data obtained from experiment.

The bulk refractive indices of the polymer material were determined using a refractometry technique, in the assumption that the refractive index $n_{\mathrm{s}}$ of the solution depends linearly upon the polymer concentration [6]. The bulk refractive index measured for the polymer OP material was $n_{p o l}=1.51$.

The effective fraction $x$ of the modified glass surface (i.e., the effective coverage with the $\mathrm{OP}$ ) was determined from the receding-water contact angle $\theta$ [12], using the Cassie's relation [15-17]:

$$
\cos \theta=x \cos \theta_{\mathrm{OP}}+(1-x) \cos \theta_{\text {glass }} .
$$

\section{Results and discussion}

To get some insight into the inner structure of the OP nanolayers, the ellipsometric measurements have been performed and the results have been fitted to the model of a 'composite' polymer film (a so-called effective medium approximation [7, 8]). This film is assumed to be made of the OP polymer and the void regions, of which volume fractions are equal to $q$ and (1-q), respectively. The resulting parameters, the average film thickness $d$ and the refractive index $n$, are plotted respectively in Fig. 1 and Fig. 2 as functions of the adsorption time $t$. The film thickness $d$ reflects the amount of immobilised OP. In its turn, the overall deviation of the refractive index $n$ of the film from the bulk OP value $\left(n_{O P}=1.51-\right.$ see the dashed line in Fig. 2 which is extrapolated using the refractometric data for the solution) measures how much the polymer volume fraction $q$ differs from $100 \%$.

The refractive index values for the layers obtained on the basis of our ellipsometric experiments demonstrate clearly that the homogeneity parameters of these layers are very different. We have almost complete homogeneity in the case of adsorption from the solutions with $C=1.0$ and $2.5 \%$ (the volume fraction of the polymer is $q=0.94-0.97$, according to Eq. (1)), and a more diluted OP obtained from the solution with $C=0.6 \%$ (then the volume fraction of the polymer is $q=0.80-0.93$ ).

Let us emphasise some important characteristics of the adsorption process for the OP built of dihydroanthracene units. A considerable heterogeneity of the adsorbed layer can be observed at the initial adsorption stage $(0-15 \mathrm{~min})$ for the specimens obtained from highly concentrated solutions $(C=1.0$ and $2.5 \%)$. Decrease in the refractive index of the layer (see Fig. 2) and abrupt oscillation of the layer thickness (see Fig. 1) in the starting time interval testify clearly heterogeneity of these specimens. The phenomenon is expressed with especial contrast in case of the $2.5 \%$ solution: the layer thickness oscillates in the interval from 88 to $38 \mathrm{~nm}$, and finally becomes equal to $60 \mathrm{~nm}$ in the equilibrium state. Such reconstructions in the adsorption layer may be explained by some changes occurring in the macromolecular conformation, along with the sorption-desorption processes. Structural rebuilding of the layers obtained from $1.0 \%$ and $0.6 \%$ solutions is expressed in a less degree at this stage, but still it is evident. 
The kinetic characteristics of the adsorption process may be explained in the following manner. Initially, the OP macromolecules in the highly concentrated solutions are immobilised on the surface only by solitary bonds. Obviously, the sorption of macromolecular conglomerates takes place, too. As a result, a rapid transition of a large amount of macromolecules on the solid surface causes rapid increase in the film thickness $(t \approx 5 \mathrm{~min}$ - see Fig. 1).

Structuring of the adsorption layer represents a more long-standing process. Therefore, reduction of the layer refractive index $(t \approx 5 \mathrm{~min}-$ see Fig. 2$)$ clearly points out that the layers obtained at this stage are heterogeneous. This is imposed by decreasing polymer volume fraction in the layers.

Rebuilding of the film structure begins at the following stages as a result of changes occurring in the macromolecular conformation. Some macromolecules that form more stable immobilisation bonds with the solid surface can build up some amount of new bonds, breaking in this way the bonds of molecules with weaker immobilisation and extruding them from the surface. The adsorbed molecules become unwrapped on the surface and occupy more surface area. Hence, the conformation changes of the macromolecules and their lowering amount on the surface stipulate rising polymer surface packing density. It is seen in Fig. 1 and Fig. 2 as decreasing film thickness and increasing layer refractive index at the next stage of the adsorption (the time interval of 5-20 min in case of the $1.0 \%$ and $2.5 \%$ solutions).

The equilibrium state is attained by the system in $20 \mathrm{~min}$ from the adsorption beginning. Both the film thickness and the refractive index become steady at this stage. Then a dynamical equilibrium is achieved among the macromolecules competing on the surface. The concentration of macromolecules on the glass surface is practically constant after that, though it is too scant to modify completely the surface.

Summing up, we should suppose that the heterogeneity of the OP adlayer is associated with the conformation rebuilding of the OP macromolecules, together with the desorption processes occurring on the glass surface.

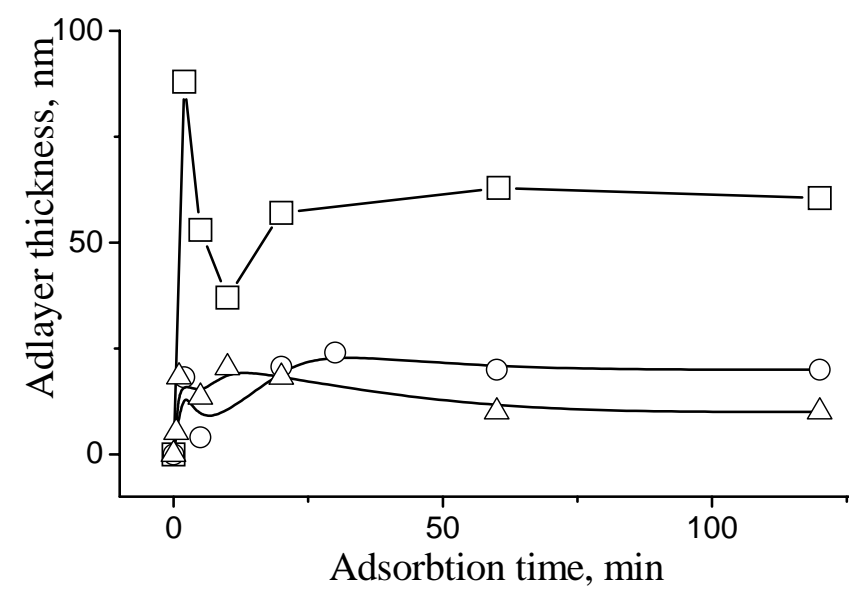

Fig. 1. Average thicknesses of the OP adlayers determined ellipsometrically as functions of adsorption time for the OP solutions with the concentrations $0.5 \%$ (triangles), $1.0 \%$ (circles), and 2.5\% (squares). Solid lines are a guide to eye. 


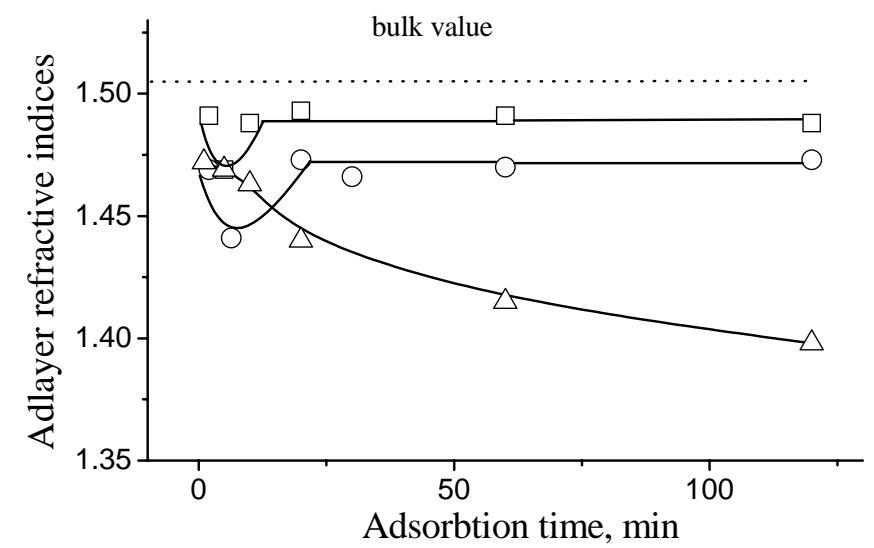

Fig. 2. Refractive indices of the OP adlayers determined ellipsometrically as functions of adsorption time for the OP solutions with the concentrations $0.5 \%$ (triangles), $1.0 \%$ (circles), and $2.5 \%$ (squares). Solid lines are a guide to eye and a dashed line denotes a bulk value extrapolated from refractometric data for the solution.

It is evident that the adsorption parameter calculated from Eq. (2) is maximal for the $2.5 \%$ solution. When the equilibrium state is achieved in this case, the corresponding value amounts to about $70 \mathrm{mg} / \mathrm{m}^{2}$. The polymer concentrations in the surface adlayers obtained from the $1 \%$ and $0.6 \%$ solutions are sufficiently lower. In the equilibrium state, the adsorption parameters are equal $23 \mathrm{mg} / \mathrm{m}^{2}$ and $10 \mathrm{mg} / \mathrm{m}^{2}$ respectively for the concentrations $1 \%$ and $0.6 \%$.

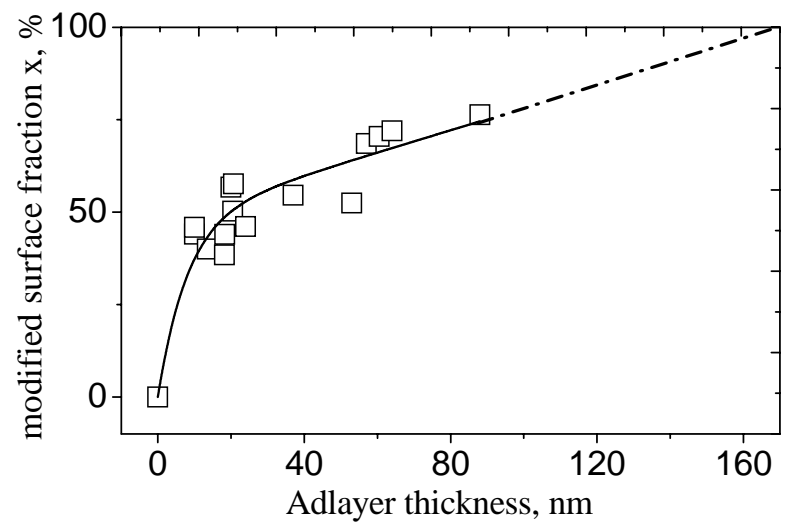

Fig. 3. Effective fraction $x$ of the glass surface modified by the adsorbed OP as a function of average adlayer thickness. Line is a guide to eye.

In order to analyse better an apparent similarity found in the contact-angle [12] and the ellipsometric data, which are well seen if their time dependences are examined, in Fig. 3 we compare the effective surface fraction $x$ of the OP modification and the average thickness $d$ of the OP adlayer. The $x$ value increases with increasing $d$ from zero to the level of $\sim 75 \%$ observed at $88 \mathrm{~nm}$. It is obvious that two different regions are available on the $x(d)$ curve: the first one is peculiar for the film thicknesses less than $30 \mathrm{~nm}$, while the second corresponds to those exceeding $30 \mathrm{~nm}$. While the adlayer thickness increases, the effective fraction $x$ of the surface modified by the OP increases rapidly (about $2.5 \%$ per nanometre) in the first region and more slowly (about $0.4 \%$ per nanometre) in the second region. 
The surface modification degree (in other words, the effective surface fraction $x$ ) depends essentially on the packing density of the OP macromolecules. Therefore, the density of the adlayers obtained under the conditions mentioned above is insufficient to modify the glass surface completely. The packing density of the macromolecules decreases for thicker layers. In particular, this feature is clearly observed for the layers thicker than $30 \mathrm{~nm}$ (Fig. 3).

A linear extrapolation of the dependence presented in Fig. 3, which is possible in the region of surface modification above $50 \%$ and for the layer thicknesses larger than $30 \mathrm{~nm}$, facilitates determining an adsorptive layer thickness necessary for complete modification of the glass surface, when the effective surface fraction $x$ would become equal to $100 \%$. The thickness of this layer must be greater than $170 \mathrm{~nm}$.

\section{Summary and conclusions}

We have formed the OP nanolayers using adsorption from the water-ammonia solution on the glass surfaces. We have shown that the thickness of the nanolayers and their structure depend on the concentration of polymer in the solution and the time of adsorption.

Changes (i.e., 'unwrapping') of the macromolecular OP conformation on the glass surface and desorption processes can explain a complex character of the adsorption kinetics. In the cases of $1 \%$ and $2.5 \%$ solutions, a steady equilibrium state is attained in the system "glass surface-OP solution" in 20 min after beginning of adsorption. For the more diluted solution $(C=0.6 \%)$, the desorption process continues for about $2 \mathrm{~h}$ and appears as decrease in the layer refractive index observed in this time interval. The maximum adsorption amount is obtained for the $2.5 \%$ solution.

Finally, we are to stress that the comparison of the ellipsometric and wettability data performed by us has given a conception about the structure of the adsorbtive surface layer.

\section{References}

1. Lupitskyy R, Roiter Y, Tsitsilianis C and Minko S, 2005. From smart polymer molecules to responsive nanostructured surfaces. Langmuir. 21: 8591-8593.

2. Minko S and Roiter Y, 2005. AFM single molecule studies of adsorbed polyelectrolytes. Current Opinion in Colloid \& Interface Sci. 10: 9-15.

3. Motornov M, Tam T, Pita M, Tokarev Ih, Katz Ev and Minko S, 2009. Switchable selectivity for gating ion transport with mixed polyelectrolyte brushes: approaching 'smart' drug delivery systems. Nanotechnology. 20: 1-8.

4. Tokarev I, Motornov M and Minko S, 2009. Molecular-engineered stimuli-responsive thin polymer film: a platform for the development of integrated multifunctional intelligent materials J. Mater. Chem. 19: 6932-6948.

5. Grossin L, Cortial D, Saulnier B, Fe'lix Ol, Chassepot Ar, Decher G, Netter P, Schaaf P, Gillet P, Mainard D, Voegel J-C and Benkirane-Jessel N, 2009. Step-by-step buildup of biologically active cell-containing stratified films aimed at tissue engineering. Adv. Mater. 21: 650-655. 
6. Kostruba A, Zaichenko A, Mitina N, Rayevska K and Hertsyk O, 2008. Kinetics of the formation and structure of oligoperoxide nanolayers and grafted polymer brushes on glass plate surface. Cent. Eur. J. Phys. 6: 454-461.

7. Herbert Wormeester, E Stefan Kooij, Agnes Mewe, Sander Rekveld and Bene Poelsema, 2004. Ellipsometric characterisation of heterogeneous 2D layers. Thin Solid Films. 455-456: 323-334.

8. Alvarez-Herrero A A, Heredero R L, Bernabeu E and Levy D, 2001. Adsorption of water on porous of Vycor of glass studied by ellipsometry. Appl. Opt. 40: 527-532.

9. Kostruba A, Stetsyshyn Yu, Zaichenko A and Mitina N, 2009. Ellipsometric ex-situ study of fluorescent oligoperoxide nanolayers with europium complexes adsorbed on a glass surface. Formation and structure. Ukr. J. Phys. Opt. 10: 175-181.

10. Semenov A A, A sketch of chemistry of natural compounds. Nauka: Novosibirsk (2000).

11. Tompkins H G, Smith S and Convey D, 2000. Optimizing the ellipsometric analysis of a transparent layer on glass. Surface and Interface Analysis. 29: 845-850.

12. Stetsyshyn $\mathrm{Yu}$, Kostruba A, Zholobko O, Zaichenko A, Mitina N and Mayevska S, 2011. Studies of the structure of oligoperoxide nanolayer with flourated bonds on the glass surface. Fiz.Khim.Tverd.Tila. 12 (to be published).

13. Azzam R M A and Bashara N M, Ellipsometry and polarized light. Mir: Moscow (1981).

14. Bootsma G A and Meyer F, 1969. Ellipsometry in the sub-monolayer region. Surface Sci. 14: 52-76.

15. Cassie A B D, 1948. Contact angles. Discuss. Faraday Soc. 3: 11-16.

16. Swain P S and Lipowsky R, 1998. Contact angles on heterogeneous surfaces: a new look at Cassie's and Wenzel's laws. Langmuir. 14: 6772-6780.

17. Lipatov Yu and Sergeeva L, Adsorption of polymers. Naukova dumka: Kiev (1972).

Kostruba A., Stetsyshyn Yu., Zaichenko A., Mitina N., Zolobko O., 2010. Ex-situ ellipsometric study of the nanolayers of dihydroantracene oligoperoxide adsorbed on glass surface. Ukr.J.Phys.Opt. 11: 269-276.

Анотація. У роботі досліджено структуру та кінетику формування наношарів нового дигідроантраченовмісного олігопероксиду в процесі адсорбиії. Встановлено залежність структури адсорбованого наношару від концентрації полімеру в розчині і тривалості проиесу адсорбиії. Кінетичні ізотерми адсорбиії мають складний характер, щзо пояснюється змінами конформації макромолекул на поверхні твердого тіла. Час встановлення стійкої рівноваги в структурі адсорбиійного наномару становить декілька десятків хвилин.

\section{$\underline{\text { Errata }}$}

Vasylkiv Yu., Savaryn V., Smaga I., Skab I. and Vlokh R. 2010. Determination of piezooptic coefficient $\pi_{14}$ of $\mathrm{LiNbO}_{3}$ crystals under torsion loading. Ukr. J. Phys. Opt. 11: 156-164.

Page 156. Instead author name: Vokh R. Should be: Vlokh R. 